\title{
Institutional Based Reasons for Students Non-participation in Physical Activity and Sport Programs in the Kenyan Public Universities
}

\author{
Bailasha N. K ${ }^{1, *}$, Rintaugu E. $\mathbf{G}^{2}$, Kamau $\mathbf{J}^{3}$, Mwangi F. $\mathbf{M}^{3}$, Mucheke C. $\mathbf{M}^{3}$, Otieno M. $\mathbf{D}^{1}$ \\ ${ }^{1}$ Department of Physical Education and Sport, University of Nairobi, Kenya \\ ${ }^{2}$ Department of Recreation and Sport Management, Kenyatta University, Kenya \\ ${ }^{3}$ Department of Physical Education, Exercise and Sports Science, Kenyatta University, Kenya
}

Received October 15, 2019; Revised December 2, 2019; Accepted December 4, 2019

Copyright $\bigcirc 2020$ by authors, all rights reserved. Authors agree that this article remains permanently open access under the terms of the Creative Commons Attribution License 4.0 International License

\begin{abstract}
University environment offers numerous advantages and easy opportunities for improving students' participation in physical activity and sport. However, there are paucity of researches on the reasons for non-participation in the university physical activity and sport programs in Kenya. The purpose of this study was to establish the institutional based reasons for the students' non-participation in the universities' physical activity and sport programs. Cross-sectional survey design was used and data was collected through questionnaires from Sixty-three (33 males, and 30 females) students. Mean standard deviation and graphs respectively, were used to describe and present data. Findings showed that key reasons for non-participation in physical activity and sport programs in the university were inadequate sport facility $74.6 \%$, overcrowded facility $73 \%$, unorganized sport program $63.5 \%$, lack of sport facility $58.7 \%$, lack of sport variety $57.1 \%$, inaccessible facility $49.2 \%$, no coaches $47.6 \%$, unfriendly time for sport $39.7 \%$, unsafe sport equipment $38.1 \%$, inappropriate behaviour of sport personnel $36.5 \%$ and $34.9 \%$ was due to unskilled sport personnel. Students' age, year and course of the study influenced non-participation of students in the universities' sport programs. Also, students' previous and current participation status confirmed students avoid universities' sport programs although they participate in the same elsewhere. Diversifying and professionalizing sport and aligning programs with academic schedules would attract students. TRA can be useful in sensitizing students on the benefits of sports. Similar studies with larger student population are necessary.
\end{abstract}

Keywords Non-participation, Palms, Physical Activity and Sport Programs, Public Universities, Sport Participation

\section{Introduction}

Participation in physical activity and sport is an integral feature of the human life, extending from health promotion (Frantz and Ngambare, 2013), social connectivity (Bartolomeo and Papa, 2017), behavior modeling (Hagger and Chatzisarantis, 2014), economic empowerment (Kirk, 2012), academic performance (Howie and Pate, 2012) and productive labor force (Lechner, 2015). Physical activity and sport is related to increased health benefits such as reduced mortality (Kokkinos, 2012), high levels of self-esteem and low levels of anxiety and stress (Dolenc, 2015). Notwithstanding the benefits of participating in physical activity and sport, the World Health Organization cited a general decline in physical activity across different age groups globally. It revealed that at least $60 \%$ of the world's population failed to meet the recommended amount of physical activity that is required to induce health benefits. Consequently, physical inactivity was classified as the fourth leading risk factor in the global mortality rate after high blood pressure, tobacco use and high blood sugar (World Health Organization, 2018).

In Kenya, the National Physical activity Action Plan 2018-2023 recognized the absence of data regarding physical activity levels in all age groups (Ministry of Health - Kenya, 2018). While university environment offers great opportunity for improving students physical activity and sport participation, research on the reasons for the students' non-participation in the universities' physical activity and sport programs in Kenya would be invaluable not only to the university management but also to the health agencies and national labor work force planners. In 
addition, the knowledge may support interventions for changing students' perception about physical activity and sport in their university life.

A number of determinants are reported to hamper students' participation in the universities' physical activity and sport programs. Empirical evidence suggests that key determinants for non-participating in physical activity and sport are ecological, physiological, social, psychological and transitional (both biological and social) (Maddison, et al. 2009; Richard, Gauvin and Raine 2011). Equally, Breuer, Hallmann and Wicker (2011); Mogaka, Bukhala,and Nguka (2017); Manz, Krug, Schienkiewitz and Finger (2016), observed that determinants of physical activity and sport have been categorized as intra-personal, inter-personal and institutional. Moreover, literature revealed that gender, age, social economic and health status influences participation in physical activity and sport (Elmagd, et al, 2018). Likewise, (Langoien et al (2017); Liangruenrom et al (2019) opined, there were specific reasons accountable to a particular determinant that influence participation in physical activity and sport in the different population categories. Consequently, Allender, Cowburn and Foster (2006); Mchunu (2008) found academic schedules and workload, inadequate and substandard sport facilities, lack of qualified coaches and inappropriate coaches' behaviour as some of the institutional based reasons for non- participation in the universities' physical activity and sport programs. This study evaluated the institutional based reasons that influenced non-participation in the universities' physical activity and sport programs by the Kenya public universities students.

This study was grounded in the Theory of Reasoned Action (TRA) (Albarrachin et al, 2001). TRA has been useful in promoting behavior changes, adaptations and interventions in the different spheres of human life. Accordingly, Saiideh et al (2018) applied TRA in health studies, Mishra, Akman and Mishra (2014) in the Communication and technology and Burak, Rosenthal and Richardson (2013): Hausenblas, Carron and Mack (1997) in the physical education and sports with positive outcome. For instance, He et al (2019), Saiideh et al (2018) and Kanani et al (2015) on separate instances applied TRA for intervention in promoting delivery through natural methods among pregnant women in China. Hosseini et al (2015) applied it in evaluating effectiveness of educational intervention to increase breakfast consumption among schoolchildren in Iran.

For the purpose of this study, the theory was useful in explaining reasons for non- participation in the universities' physical activity and sport programs. It would therefore be essential in recommending remedial intervention for the non-participation. According to the theory, the underlying reasons for non-participation in the universities' physical activity and sport programs could be traced to the students' beliefs about their life before, during and even after campus. Their perceived significant others and peer support, or their interpretation of their living environment and the social norms in relation to physical activity and sport participation. Therefore, the TRA is essential in explaining the reasons influencing students' choices in conforming or changing their behaviour towards participating in the universities' physical activity and sport programs.

\section{Purpose of the Study}

The purpose of the study was to establish the institutional based reasons that influenced non-participation in the universities' physical activities and sports programs by the Kenyan public university students.

\section{Objectives}

To evaluate reasons and the influence of' age, birth rank, year of study, course of study and the previous and current sports participation status on non-participation in the public universities' physical activity and sport programs by the students.

\section{Materials and Methods}

The target population was the students in the Biological and Physical Sciences, Education and External Studies, Engineering and Architecture, Health Sciences and Humanities and Social Sciences Colleges of the University of Nairobi-Kenya. The study design was cross-sectional survey. The sample size was eighty- four (45 females, 39 males) students but only sixty- three ( 33 males, and 30 females) duly filled the questionnaire and was used for this study. The Sample selection was via random inquiry of the students' participation status in the universities' physical activity and sports programs. Administration of sample selection was at the end of the lecture during the $7^{\text {th }}$ week of the second semester of 2017/2018 academic year. The selected students were explained study's purpose when they volunteer by signing the consent form. The instrument for data collection was an adaptation of the Physical Activity and Leisure Motivation Scale (PALMS). The extensive use of PALMS to determine the motives of participating in physical activity and sports for leisure has been useful in producing knowledge in realms of sport (Kueh, Kuan and Morris, 2017: Zach et al, 2012).

\section{Results and Discussion}

Figure 1 show that students' in age categories 17-19 (36.5\%) and 20-22 (52.4\% years accounted for majority (89\%) of the non-participants in the universities' physical activity and sport programs. The trend of non-participating students seemed to reduce with advancing age category $23-25(9.5 \%)$ and "over 26 " (1.6\%) years. The finding 
indicate that age influences non-participation of students' in the universities' physical activity and sport programs. Our findings agrees with (Elmagd, et al, 2018) that age, gender, socio-economic status, knowledge of the sport benefits, attitudes toward sports participation and health factors influence the declining participation rate in physical activity among adolescents and college age students. The finding suggests that the first and the early second year students mostly, do not participate in the universities' physical activity and sports programs. Possibly, the transiting challenges or students unfamiliarity with university environment may influence non-participation. Transition from secondary to university presents students with challenges. Deliens et al (2015) found that students' transition from secondary to university is often accompanied by unhealthy behaviour changes like decreasing physical activity and increasing sedentary behaviour. Therefore, continued education on benefits of sports and awareness of the available physical activity and sport programs may be useful in changing students' attitude towards universities' physical activity and sport programs.

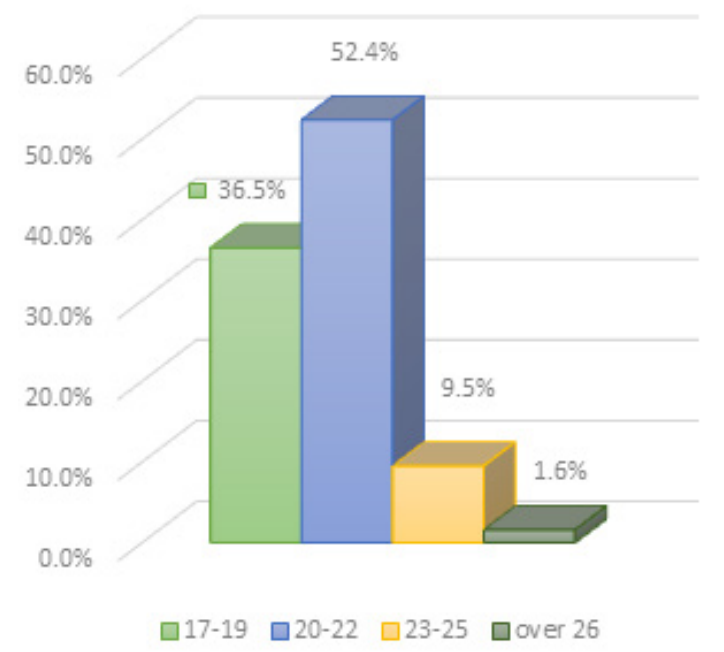

Figure 1. Students' age and non-participation in the university physical activity and sport programs

Figure 2 details how students' birth rank influenced their non-participation in the physical activity and sport programs in the Kenyan public universities. Finding of the study does not show any particular trend. It would be essential for further studies with a larger group of students as we could not trace related literature to corroborate our findings. However, in the official blog of the Pathways to the Podium Research Project 2012 reported a high likelihood in the later-born children becoming elite athletes while first-born children becoming pre-elite or non-elite athletes. Older siblings of elite athletes being nearly 2.5 times more likely to have participated in general fitness activities on a regular basis than older sibling of non-elite athletes. Older sibling of elite athletes being more than twice likely to have participated in recreational sports on a regular basis than older sibling of non-elite athletes. Younger sibling of elite athletes being nearly 4 times more likely to have participated in competitive sport on a regular basis than younger sibling of non-elite athletes, and, siblings of elite athletes being more likely to have participated in competitive sport at the elite and pre-elite levels than sibling of non-elite athletes.

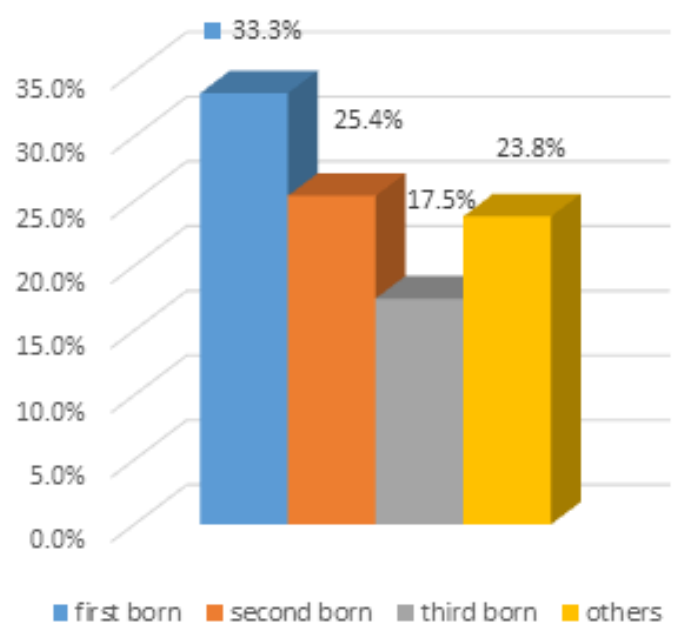

Figure 2. Students' birth rank and non-participation in the university physical activity and sport programs

Figure 3 describes students' non-participation in the universities' physical activity and sports programs according to the year of study. The finding shows that majority $(71.4 \%)$ of the non-participating students were in the first (34.9\%) and fourth (36.5) year of study. Still, the finding show a declining trend of students' non-participation between second (12.7\%), third (6.3\%), fifth $(3.2 \%)$ and sixth $(1.6 \%)$ year. It is therefore evident that most non-participating students' in the universities' physical activity and sports programs are first and fourth years. In addition, students' non-participation in the university sports programs seem to decline with advancing year of study. In a similar study in china (Abdullah, Wong, Yam \& Fielding, 2005) also did report conclusive findings. Since, we could not locate much literature to corroborate our finding; we suggest similar studies with a larger sample size.

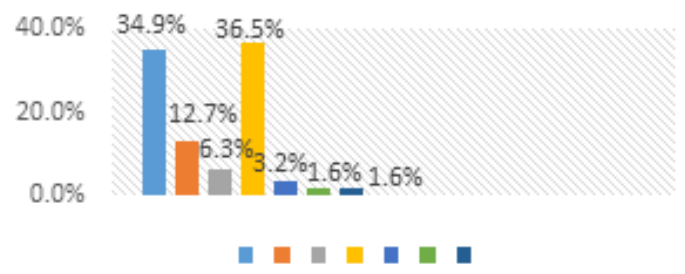

Figure 3. Students' year of study and non-participation in the Universities' physical activity and sports

Figure 4 describes the influence of the students' course of study on the non-participation in the universities' physical activity and sports programs. The finding showed 
that the course of study; Bachelor of arts (31.7\%), Bachelor of education arts (31.7\%), Bachelor of science (14.3\%), Bachelor of education Science (7.9\%) Bachelor of Science Civil engineering (7.9\%), Bachelor of law (3.2\%) and Bachelor of medicine (3.2\%) influenced students' non-participation in the universities sports programs in the Kenyan public universities. Although not precisely related, Calisine et al, 2017 alluded that students course load is was negatively associated with vigorous physical activity. We suggest for further studies with larger group of students to corroborate the findings of this study.

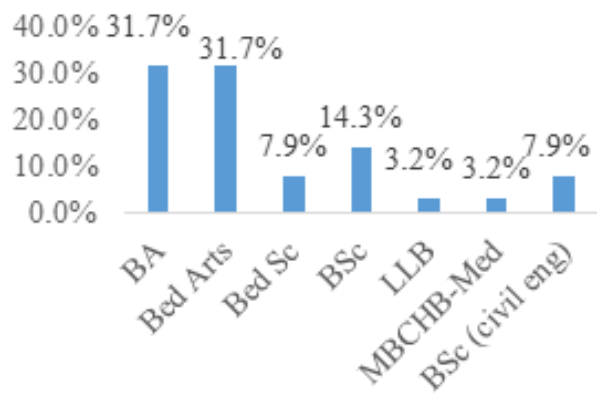

Figure 4. Students' course of study and non-participation in the university physical activity and sport programs

In Figure 5 details the students' status on physical activity and sports participation. After securing information on the students' non-participation in the universities physical activity and sports programs status. We sought further about their physical activity and sports participation status currently. The finding showed that while they did not participate in the university based physical activity and sports programs, majority of the students $(69.8 \%)$ agreed they participated in physical activity and sports. This study did not inquire how or where they participated in the activities. We suggest for a study to determine other source of the physical activity and sports programs for the university students in the Kenyan public universities.

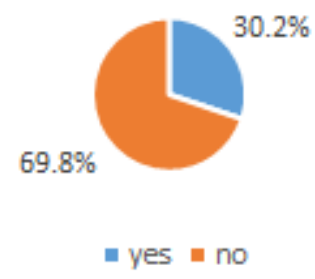

Figure 5. Students' current physical activity and sports participation status

The details of figure 6 described the students' previous participation in sports. The findings indicated that majority (81\%) of the students' non-participating in the universities' physical activity and sports programs, initially participated in physical activities and sports. These findings may be of concern to the university management as to the reasons for sudden change of sports participation in the university. Nevertheless, our finding confirms ((Elmagd, et al, 2018) observations that participation in sports among college age students is declining.

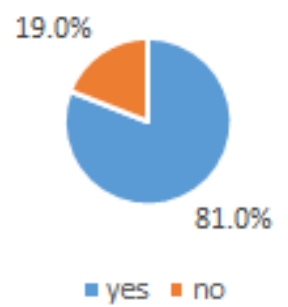

Figure 6. The students' previous participation in the physical activity and sports

Figure 7 described the frequency of participating in sports among students who do not participate in the universities' physical activity and sports programs. The findings indicated that (52.4\%) participated once a week, while only (19\%) reported to be involved twice and three times a week respectively. The findings showed that students who did not participate in the universities' physical activity and sports programs also, did not do physical activities enough number of times per week to induce health benefits (WHO, 2018).

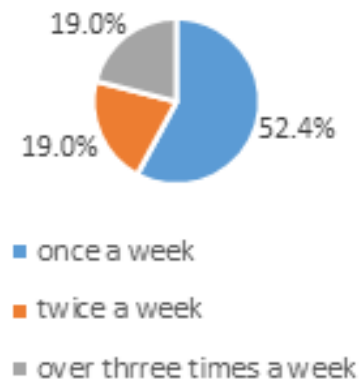

Figure 7. Students' frequency of participating in physical activity and sports

Figure 8 details the institutional based reasons for the students' non-participation in the Kenyan public universities' physical activity and sports programs. The responses were measured a five Likert scale but since our aim was to report on agreement/disagreement status of the students reasons for non-participation in sports, it was condensed to three steps agree, no idea and disagree. 


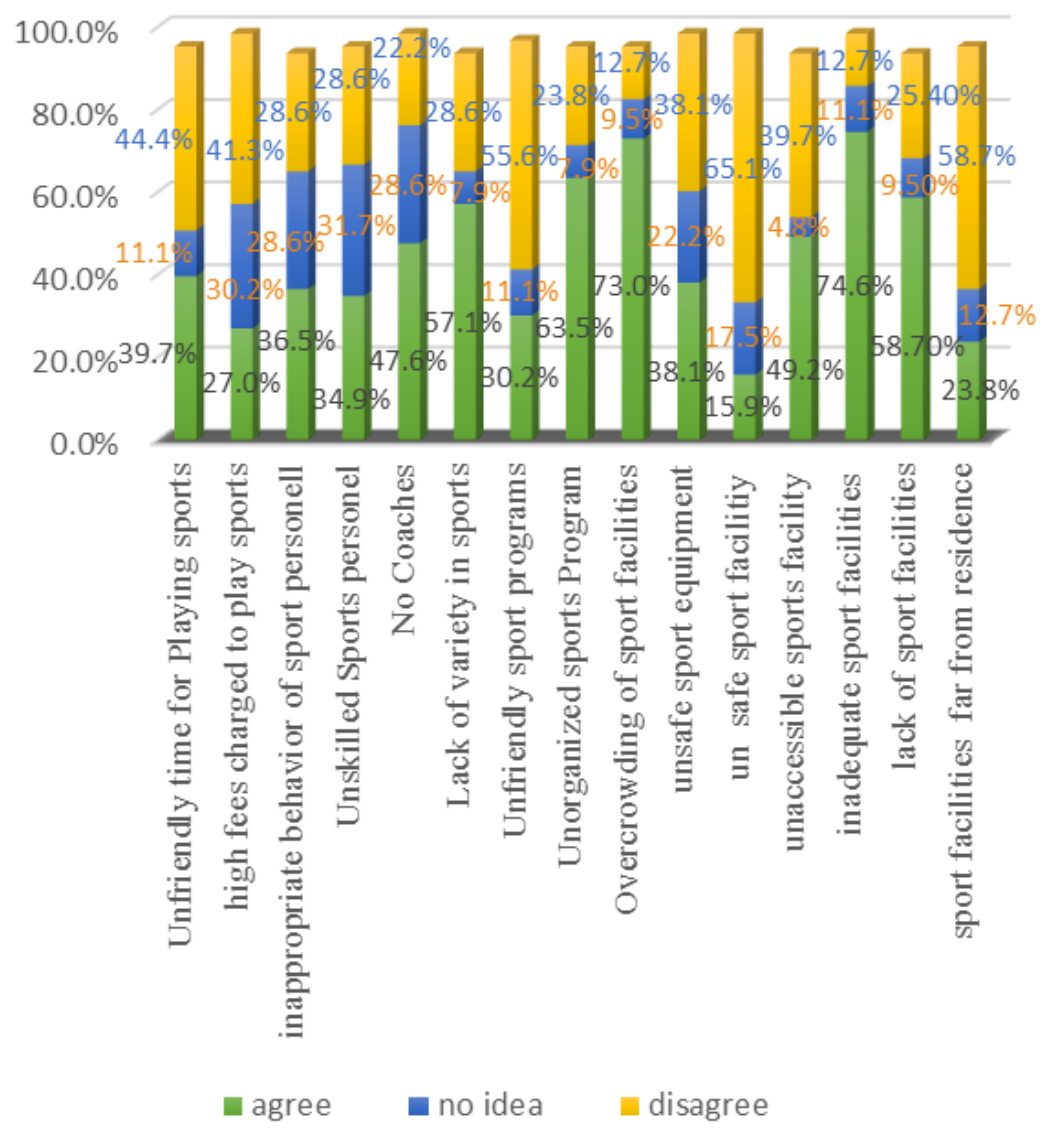

Figure 8. Students' institutional based reasons for non-participation in the public university physical activity and sport programs in Kenya

According to the findings, most students agreed inadequate sports facility $74.6 \%$, overcrowded facility $73 \%$, unorganized sport programs $63.5 \%$, lack of sports facility $58.7 \%$, lack of sports variety $57.1 \%$, and inaccessible facility $49.2 \%$, no coaches $47.6 \%$, as the key factors influencing their non-participation. However, they disagreed with unsafe facility $65.1 \%$, sport facilities are far from the residence $(58.7 \%)$, unfriendly sports programs $(55.6 \%)$, high entry fees $(41.3 \%)$ and unfriendly playing times $(44.4 \%)$ influence for their non-participation in the universities' physical activity and sports programs. Our finding supports Summersets \& Hoare (2018) that accessibility to sport facility is a barrier to voluntary sports participation among children under 18 years. Other authors have reported similar finding. Charlton et al, (2010), reported that among the external barriers to physical activity, the most obvious influence on participation lies beyond control of the individual. They cited physical environment cleanliness and safety, design of the facility to accommodate everyone even persons with special needs, closeness of facility to residents, quality of service provision and ease of access to reliable up-to-date information about services that promote awareness and the intention to participate in sports as the key external factors.

\section{Conclusions}

According to the findings, students' age, year and course of the study influence participation in the universities' physical activity and sports programs. That inadequate sports facility, overcrowded facility, unorganized sport programs, lack of sports facility, lack of sports variety, inaccessible facility and lack of coaches were the specific institutional based reasons that influence non-participation in the Kenyan public universities' physical activity and sport programs.

\section{Recommendations for Implementation and Further Studies}

The university management needs to provide adequate sporting infrastructure, create awareness of the available sport programs, provide qualified sport personnel and align co-curricular activities with the academic schedule. Physical activity and sport programs need to be structured according to gender, year and the course of study of students. TRA can be useful in isolating sporting needs of the students in the university. 
Studies to establish social, psychological, technical and economic determinants of students' who do not participate in the universities' physical activity and sport programs are necessary.

\section{REFERENCES}

[1] Albarrachin, D., Johnson, B.T., Fishbein, M. \& Muellerleile, P.A. (2001): Theories of Reasoned Action and Planned Behavior as Models of Condom Use: A Meta-Analysis: Psychology Bulletin. 2001.

[2] Allender, S., Cowburn, G. \& Foster, C. (2006): Understanding Participation in Sport and Physical Activity among Children and Adults: a review of qualitative studies. Health Education Research, volume 21, issue 6, 1 December 2006, pgs 826-835.

[3] Bartolomeo, G. \& Papa, S. (2017): The Effects of Physical Activity on Social Interactions: The Case of Trust and Trustworthiness. Journal of sports economics. July 5, 2017.

[4] Burak, L. J., Rosenthal, M. \& Richardson, K. (2013): Examining attitudes, beliefs, and intentions regarding the use of exercise as punishment in physical education and sport: an application of the theory of reasoned action. Journal of applied Social psychology. July 2013: volume 43, Issue 7 Pages $1436-1445$.

[5] Breuer, C., Hallmann, K. \& Wicker, P. (2011): Determinants of Sport Participation in Different Sports (2011): Managing Leisure 16 (4):269-286

[6] Calestine, J., Bopp, M., Bopp, C \& Papalia, Z (2017): College Student Work Habits are Related to Physical Activity and Fitness. International Journal of Exercise Science, 2017; 10(7): 1009-1017.

[7] Charlton, A., Potter, M., McGinigal, S., Romanou E., Slade, $\mathrm{Z}$ and Hewitson, B. (2010): Barriers to participation. Analysis to inform the development of the 2010/11 Taking Part Survey. Department for Culture Media and Sports. August 2010

[8] Deliens, T, Delforche, B, De bourdeaudhuij, Clarys, P. (2015) \& I: Determinants of physical activity and sedentary behaviour in university students: a qualitative study using focus group discussions. BMC Public Health, 15. Article no: 201. 2015

[9] Dolenc, P. (2015): Anxiety, Self-Esteem and Coping with Stress of Secondary School Students in Relation to Involvement in Organized Sports. Slovenia Journal of Public Health 2015 September; 54(3): 222-229.

[10] El-Gilany, A-H., Badawi, K., El-Khawaga, G. \& Awadalla, N.(2017): Physical activity profile of students in Mansoura University, Egypt: Eastern Mediterranean Health Journal Vol. 17 No. 8, 2011.

[11] Elmagd, M. A., Tiwari, U, Mossa, A. H. \& Tiwari, D. (2018): Barriers of Sports Participation in Higher Education in the UAE. Journal of Physical Therapy and sports Medicine (2018) vol. 2, Issue 2.
[12] Frantz, J. M. \& Ngambare, R. (2013): Physical Activity and Health Promotion Strategies among Physiotherapists in Rwanda. Africa Health Sciences. 2013, March; 13 (1):17-23.

[13] Gavin, J., Keough, M., Abravanel, M., Moudrakovski, T. \& Mcbrearty, M. (2014). Motivations for Participation in Physical activity across the Lifespan. International Journal of Wellbeing. 4 (1), 4661.

[14] Hagger, M.S. \& Chatzisarantis, N. L.D. (2014): An Integrated Behavior Change Model for Physical Activity, Exercise and Sport Sciences. Reviews. April 2014 - volume 42 issue- 2 page 62-69.

[15] Hausenblas, H., A., Carron, A., V. \& Mack, D., E. (1997): Application of the Theories of Reasoned Action and Planned Behavior to Exercise Behavior: A Meta-Analysis. Journal of Sport \& Exercise Psychology 19(1):36-51: March 1997.

[16] He, J., Wan, L. \& Luo, B. (2019): Intentions and Influencing Factors regarding Childbirth among Urban Pregnant Women in China, Based on the theory of reasoned Action and Structured Equation Modeling. Journal of International Medical Research: 2019 Sept, 47 (9); 4482-4491.

[17] Hosseini, Z., Gharghani, Z.G, Mansoori, A., Aghamolaei \& Nasrabadi, M. M. (2015): Application of the Theory of Reasoned Action to Promoting Breakfast Consumption. Medical Journal of the Islamic State of Iran. Iran University of Medical Sciences. 2015; 29: 289.

[18] Howie, E. K. \& Pate, R.R (2012): Physical activity and academic achievement in children: A historical perspective. Journal of sport and Health Science. Volume 1, Issue 3, December 2012, page 160-169. Open access.

[19] Kanani, S., Allahverdpour, H. \& Asgharijafarabadi, M. (2015): Modeling the Intention to Choose Natural Virginal Delivery using Reasoned Action \& Cognitive theories. Health Promotion Perspectives: 5 ; (1) 24-33.

[20] Kindric, M., Sindic, J., Furjan-Mandic, G. \& Schiefler, B. (2013): Participation Motivation and Student's Physical Activity among Sport Students in Three Countries. J Sport science Med. 2013 Mar; 12(1): 10-18.

[21] Kirk, D. (2012): Empowering Girls and Women through Physical Education and Sport Advocacy Brief. Bangkok: UNESCO Bangkok, 2012. UNESCO Asia and Pacific Regional Bureau for Education. ISBN 978-92-9223-396-9 Electronic version

[22] Kokkinos, P. (2012): Physical Activity, Health Benefits, and Mortality Risks. International Scholarly Research Network ISRN Cardiology Volume 2012. Published online 2012 Oct 30.

[23] Kueh, Y., Kuan, G \& Morris, T. (2017): The Physical Activity and Leisure Motivation Scale: A confirmatory study of the Malay language version. International journal of sport and exercise

[24] Langoien, L., J., Terragni, L., Rugseth, G., Nicolaou, M., Holdsworth, M., et al, (2017): Systematic mapping review of the factors influencing physical activity and sedentary behaviour in ethnic minority groups in Europe: a DEDIPAC study. International Journal of Behavioral, Nutrition and Physical activity. 2017. 14:99.

[25] Liangruenron, N., Craike, M., Biddle, S. J. H., Suttikasem, K. 
and Pedisic, Z. (2019): Correlates of physical activity and sedentary behaviour in the Thai population: A systematic review. Biomedical journal of Public Health. 2019, 19: 414.

[26] Lechner, M. (2015): Sports, Exercise, and Labor market Outcomes: Increasing Participation in Sports and Exercise can Boost Productivity and Earnings. IZA World of Labor. Evidence- based Policy Making. February 2015

[27] Lim, K. C. (2009): University Students' Attitude, Self-efficacy and Motivation regarding Leisure Time Physical Participation. Journal Pendidik dan Pendidikan. Jl. 24, 1-15, 2009.

[28] Maddison, M.,Vander Hoorn, S., Jiang,Y., Ni Mhurchu, C., Exeter, D...... et al. (2009): The Environment and Physical Activity: The Influence of Psycho Social, Perceived and Built Environmental Factors. International journal of Behavioral, Nutrition and Physical activity V. 6:19. Open access.

[29] Manz, K. Krug, S. Schienkiewitz, A. \& Finger, J. D. (2016): Determinants of organized Sports Participation Patterns during the Transition from Childhood to Adolescence in Germany: Results of a Nationwide Cohort study. Biomedical journal of Public Health. 2016; 16(1): 939.

[30] Mchunu, S.J.A (2008): Reasons for Non-participation in Sports by Black learners at the Secondary School Level. Unpublished Master of Education Thesis. University of South Africa.

[31] Mishra, D., Akman, I. \& Mishra, A. (2014): Theory of Reasoned Action Application for Green Information Technology Acceptance. Computers in Human Behavior. 36 (6): 29-40.

[32] Mogaka, E., Bukhala, P. \& Nguka, G. (2017): Determinants of Participation in Physical Activity among School Going Adolescents with Disabilities in Kakamega County, Kenya. IOSR Journal of Sports and Physical Education (IOSR-JSPE), Volume 4, Issue 4 (Jul. - Aug 2017), PP 42-52. www.iosrjournals.org

[33] Richard, L., Gauvin, L. \& Raine, K. (2011): Ecological Models Revisited; Their Uses and Evolution in Health Promotion Over Two Decades. Annual Review of Public Health, Vol. 32:307-326, 2011.

[34] Saiideh, N., Fatemeh, M. \& Fariba, S. (2018): Effectiveness of Trainings Based on the Theory of Reasoned Action in the Choice of Natural Delivery by Pregnant Women. International journal of Women's Health and Reproductive Sciences. Vol 6 No 2, April 2018. Open Access.

[35] Somerset, S \& Hoare, D. J. (2018): Barriers to voluntary participation in sport for children: a systematic review. BMC Pediatrics volume 18, Article number: 47 (2018)

[36] The Expert Advantage: Faster, higher, stronger... and younger? Birth order, sibling sport participation, and sport expertise development. The official blog of the Pathways to the Podium Research Project. https://expertadvantage.wordpress.com/2012/06/19/siblings/

[37] United Nations Development Program (2018): Global Goals, Local Action. Global week 2018.

[38] http://www.undp.org/content/undp/en/home/sustainable-dev elopment-goals/goal-3-good-health-and well-being.html
[39] World health organization (2018): Kenya National Physical Activity Action plan 2018-2023. Ministry of Health. Department of Non- Communicable Diseases. Kenya.

[40] Zach, S., Bar - Eli, M., Morris, T. \& Moore, M. (2012): Measuring Motivation for Physical Activity: An Exploratory Study of PALMS -The Physical Activity and Leisure Motivation Scale. Athletic Insight. The online journal of sport psychology: Inc, ISSN 1536-0431 